\title{
Klasifikasi Topeng Cirebon Menggunakan Metode Convolutional Neural Network
}

\author{
Felix Indra Kurniadi ${ }^{1}$, Vinnia Kemala Putri ${ }^{2}$, Yohanes Eka Wibawa ${ }^{3}$ \\ ${ }^{1,3}$ School of Engineering and Technology: Informatics Engineering, Tanri Abeng University, \\ Jakarta, Indonesia \\ 1.felixindra@tau.ac.id, ${ }^{2}$ vinnia.kemala51@ui.ac.id, ${ }^{3}$ yohanes.eka@tau.ac.id \\ ${ }^{2}$ Fakultas Ilmu Komputer, Universitas Indonesia, Depok, Indonesia
}

\begin{abstract}
Cirebon mask is one of the intangible cultural heritage in Indonesia. It is one of the prominent cultural assets from Cirebon and becoming one of the identity Cirebon culture. However, the current condition people tend to forget the cultural asset and lack of help from the government makes the Cirebon mask become the third-rate assets. Our concern lays on the extinction of this Mask. We want to implement digitation and automatic identification using image processing techniques. In this paper, we applied the Convolutional Neural Network for Cirebon Mask classification.
\end{abstract}

Index Terms-Cirebon Mask, Deep learning, convolutional neural network, Indonesian culture.

Abstrak - Topeng Cirebon merupakan salah satu warisan budaya takbenda di Indonesia. Ini adalah salah satu aset budaya unggulan dari Cirebon dan menjadi salah satu identitas budaya Cirebon. Namun, kondisi masyarakat yang cenderung melupakan aset budaya dan kurangnya bantuan dari pemerintah menjadikan topeng Cirebon menjadi aset kelas tiga. Keprihatinan kami terletak pada punahnya Topeng ini. Kami ingin menerapkan digitasi dan identifikasi otomatis menggunakan teknik pemrosesan gambar. Dalam makalah ini, kami menerapkan Jaringan Syaraf Tiruan Konvolusional untuk klasifikasi Topeng Cirebon.

Istilah Indeks - Topeng Cirebon, Pembelajaran mendalam, jaringan saraf konvolusional, budaya Indonesia.

\section{PENDAhUluan}

Indonesia merupakan salah satu negara yang memiliki banyak kebudayaan baik dari lukisan, topeng, tarian dan senjata. Salah satu kekayaan tersebut adalah topeng Cirebon dari Jawa Barat. Topeng ini merupakan perwujudan akulturisasi antara adat dan budaya Cirebon dengan agama[1].

Topeng Cirebon sendiri merupakan sebuah ornament penting yang digunakan dalam pertunjukan tari topeng Cirebon. Pertunjukan tari topeng Cirebon sering digunakan untuk pertunjukan hiburan dan upacara keadatan [1].

Sayangnya keindahan dari topeng Cirebon ini tidak diketahui oleh banyak orang, bahkan perhatian pemerintahan terhadap keberlangsungan topeng Cirebon sangat minim. Hal ini dikhawatirkan dengan pergeseran kebudayaan, kebudayaan topeng Cirebon akan dilupakan oleh masyarakat Indonesia.

Didasari dengan problem yang terjadi saat ini maka peneliti ingin melakukan proses digitalisasi dan proses pengklasifikasian topeng Cirebon. Proses ini dilakukan untuk menjaga kebudayaan Indonesia terutama topeng Cirebon agar tidak menghilang tergerus oleh jaman. 
Sayangnya proses pengklasifikasian topeng Cirebon bukanlah perkara yang mudah. Hal ini dikarenakan topeng Cirebon memiliki banyak keunikan dari tampilannya maupun ornamennya sehingga proses pengenalan akan sulit dilakukan[1]. Alasan inilah yang membuat penulis ingin membuat sebuah system pengklasifian topeng Cirebon secara automatis

Pengklasifikasian topeng Cirebon pernah dilakukan oleh Kurniadi. Kurniadi mengusulkan penyelesaian klasifikasi topeng Cirebon menggunakan metode robust statistic menggunakan $z$ score untuk mencari data yang dianggap sebagai outlier. Metode yang diusulkan oleh Kurniadi memberikan hasil penambahan akurasi akan tetapi kelemahan terbesar dari penelitian ini adalah penggunaan metode ekstraksi fitur yang sederhana dalam menyelesaikan data yang kompleks [2]. Kurniadi juga mengusulkan penelitian mengenai penyelesaian problem dalam ekstraksi ciri topeng Cirebon dengan menggunakan metode GLCM, sayangnya proses pengekstrasian ciri ini tidak memberikan hasil yang memuaskan, banyak sekali kekurangan seperti fitur yang belum merepresentasikan dengan baik topeng [1].

Saat ini penelitian terhadap topeng Cirebon masih sedikit, oleh karena hal ini maka untuk mendapatkan sebuah keterbaruan yang layak digunakan dalam proses klasifikasi dari topeng Cirebon maka perlu dilakukan proses pencarian state of the art dari berbagai penelitian yang mencoba menyelesaikan permasalahan klasifikasi dan identifikasi terhadap budaya Indonesia lainnya.

Penelitian pernah dilakukan untuk menyelesaikan permasalahan klasifikasi terhadap warisan budaya Indonesia. Harjoko et.al. mencoba mengatasi permasalahan terhadap klasifikasi topeng Bali menggunakan Convolutional Neural Network. Hasil yang diberikan dengan menggunakan metode CNN sudah baik walaupun dalam beberapa kasus tidak mampu membedakan topeng yang kompleks [3].

Fokus pada penelitian ini memperbaiki problem pencarian fitur yang menggunakan system human-crafted seperti yang dilakukan oleh [1], [2] dan mengganti pencarian feature dengan konsep machine-crafted. Sehingga kami menggunakan metode deep learning terutama convolutional neural network sebagai metode yang digunakan dalam proses pengklasifian topeng ini. Berdasarkan Arsa [4], Deep learning sangat berkembang terutama dalam representasi fitur, sehingga lebih invariant terhadap rotasi dan scaling [4].

Kelemahan terbesar dalam pembelajaran menggunakan deep learning adalah dibutuhkannya data yang banyak sehingga dibutuhkan hardware komputasi yang lebih mumpuni. Problem ini dapat diselesaikan dengan menggunakan konsep dari transfer learning. Pada penelitian ini kita akan menggunakan VGG19 sebagai fitur ekstraksi,

Kontribusi penulis dalam penelitian ini adalah:

1. Proses digitalisasi dan identifikasi automatis berbasiskan pendekatan artificial intelligence

2. Pengimplementasian metode CNN dengan transfer learning menggunakan VGG 19

Jurnal ini terdiri atas 5 bagian. Pada Bagian I akan menjelaskan mengenai pendahuluan, pada Bagian II akan menjelaskan dasar-dasar teori yang digunakan dalam penelitian ini, Bagian III akan menjelaskan Metodologi yang dilakukan, Bagian IV akan menjelaskan mengenai eksperimen yang akan dilakukan beserta data yang digunakan dan data Bagian $\mathrm{V}$ akan menjelaskan mengenai kesimpulan yang didapatkan dari penelitian ini.

\section{LANDASAN TEORI}

Pada Bagian ini akan menjelaskan beberapa teori dasar yang mendukung penelitian ini. Secara berurutan akan dijelaskan mengenai Topeng Cirebon, Convolutional Neural Network 


\section{a. Topeng Cirebon}

Topeng Cirebon diciptakan oleh Sunan Kalijaga ydengan Sunan Gunung Jati. Awalnya, topeng Cirebon digunakan sebagai alat untuk berdakwah dan menyebarkan agama islam di pesisir utara pada abad ke-15. Representasi topeng Cirebon didasari oleh cerita Panji yang berasal dari kerajaan Jenggala Jawa Timur [5].

Topeng Cirebon sendiri memiliki lima jenis topeng yang paling terkenal dan sering digunakan dalam pertunjukan yaitu Panji, Samba, Rumyang, Kelana dan Tumenggung. Gambar 1. Memberikan gambaran kelima jeni topeng Cirebon.

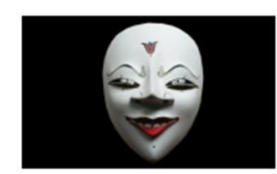

(a)

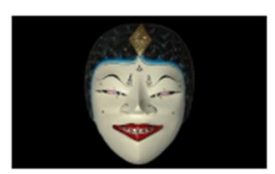

(b)

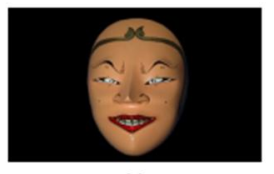

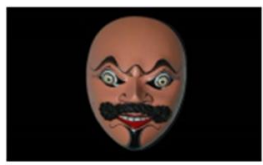

(d)

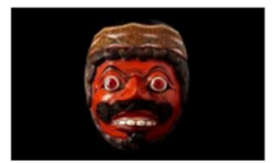

(e)

Gambar 1. Jenis-jenis topeng Cirebon: a) Panji b) Samba c) Rumyang d) Tumenggung e) Kelana

Setiap topeng Cirebon memiliki karakteristik penokohan yang unik dan terkadang kompleks seperti sifat manusia dimana Panji yang bertindak sebagai gambaran bayi yang baru lahir dan kewibaan dari seorang raja dimana Panji memiliki ketenangan dan kewibawaan. Samba merepresentasikan sikap suka merendah setia kawan dan penuh kaingin tahuan. Rumyang merepresentasiakan seseorang yang penuh dengan rasa ingin tahu terhadap lingkungan sekitarnya dan refleksi diri dalam keragu-raguan. Tumenggung merepresentasikan kedewasaan dan kemauan keras serta keberanian dan ambisius.Klana merepresentasikan Hasrat duniawi yang penuh nafsu dan kekerasan [6].

\section{b. Convolutional Neural Network}

Convolutional Neural Network adalah salah satu state of the art dalam dunia Deep learning. CNN network terdiri atas 4 layer utama yaitu convolutional layer, pooling layer, fully connected layer dan klasfikasi layer[4].

Proses konvolusi adalah sebuah konsep dasar dari Convolutional Neural Network. Proses ini digunakan untuk mencari tepi dari sebuah gambar yang sering disebut sebagai high-level fitur. First layer of convolutional yang terhubung dengan gambar digunakan untuk mengambil fiturfitur dasar dari gambar seperti: warna, tepi, gradient orientation dan lain-lainnya. Proses konvolusi $\mathrm{g}(\mathrm{x}, \mathrm{y})$ dapat diekspresikan [4]:

$$
g(x, y)=w * I(x, y)
$$

Dimana w merupakan kernel dan I(x,y) adalah gambar yang dijadikan sebagai input.

Pooling layer diletakan setelah convolutional layer dimana layer ini digunakan untuk mengurangi ukuran dimensi. Secara intuitif, proses ini sangat penting dilakukan untuk 
mengurangi computational cost dengan mereduksi dimensi dari fitur yang didapatkan dari convolutional layer. Selain itu juga bagian ini penting untuk mengambil fitur yang dominan sehingga membuat lebih invariant terhadap rotation dan posisi. Secara umum terdapat dua pooling yang sering digunakan yaitu max pooling dan average pooling [4]. Konsep average pooling dan max pooling dijelaskan pada gambar 2 .

Pada layer terakhir dari CNN memiliki kegunaan untuk menentukan kelas dari data yang digunakan. Pada layer ini digunakan untuk mempelajari kombinasi non-linear dalam high-level features yang diproduksi dari convolutional layer. Penggunaan metode Softmax digunakan untuk melakukan proses klasifikasi.
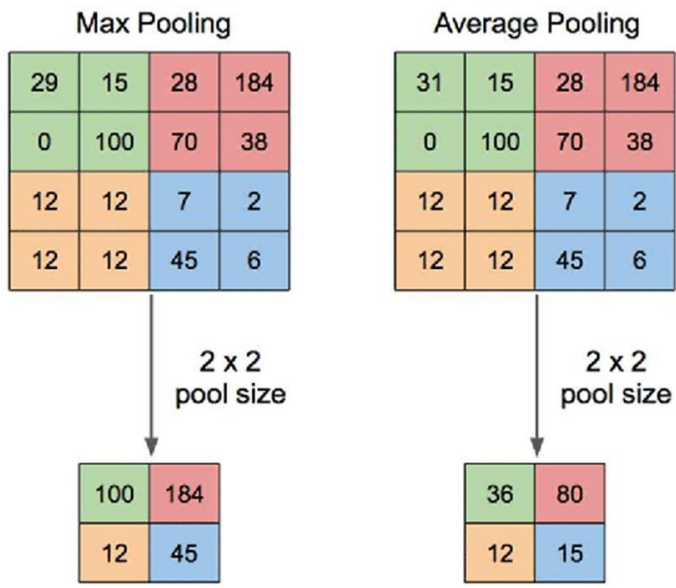

Gambar 2. Konsep Max Pooling dan Average Pooling pada pooling layer [7]

\section{Metodologi}

Pada Bagian ini akan dibahas mengenai proses transfer learning dengan menggunakan VGG16 dan juga menjelaskan evaluasi yang digunakan.

\section{a. Transfer Learning}

Transfer learning [8] merupakan proses mentransferkan weight dari pre-trained model dan kemudian di fine-tuned dengan model menggunakan dataset yang dimiliki. Hal ini dilakukan untuk mengurangi kesulitan dalam proses training dalam arsitektur deep learning. Dibandingkan melatih keseluruhan arsitektur dengan weight yang bernilai acak, kita menggunakan weight dari pre-trained model dan fokus pada layer yang lebih penting di dalam proses training. Pre-trained model sendiri adalah sebuah network yang sudah dilatih orang lain dengan data yang sangat besar.

Penelitian ini menggunakan VGG16 [9] sebagai pre-trained model yang digunakan. VGG16 bertindak sebagai fixed feature extractor. Kita tidak mengubah nilai weight pada setiap layers kecuali nilai pada 4 layer terakhir dari VGG16. Kita menggantinya dengan 1024 neurons FC layer, sebuah drop out layer untuk regularisasi dan softmax sebagai classification layer. Gambar 3 akan memberi gambaran mengenai konsep yang digunakan pada penelitian ini.

Secara garis besar input gambar di feed-forward ke dalam VGG 16, hasil output dari arsitektur max pooling dari VGG 16 digunakan untuk merepresentasikan fitur dari gambar input. Selanjutnya fitur dimasukkan ke dalam Fully Connected Layer dan di flatten menjadi 1024 neuron. Kemudian menurunkan sebanyak 50\% neuron secara random pada dropout layer untuk membuat network agar tidak fit dengan training data. Selanjutnya dimasukkan ke dalam softmax untuk proses klasifikasi [10]. 


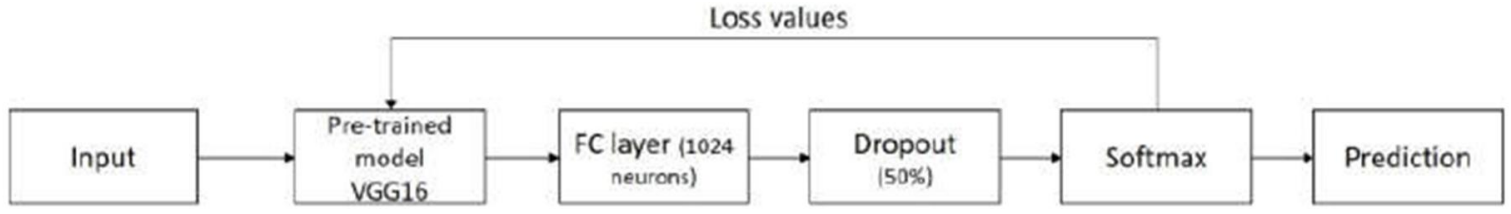

Gambar 3. Arsitektur yang Digunakan Dalam Penelitian Ini [10]

\section{b. Pengukuran Evaluasi}

Proses evaluasi pada penelitian ini akan menggunakan akurasi

$$
\text { akurasi }=\frac{t p+t n}{t p+t n+f p+f n} * 100 \%
$$

Dimana tp, th, fp dan fn merupakan true positive, false positive, true negative dan false negative. Konsep ini diambil dari confusion matrix.

\section{EKSPERIMEN DAN HASIL}

Pada bagian ini akan dijelaskan mengenai data yang digunakan dalam eksperimen beserta hasil yang didapatkan.

\section{a. Data}

Data dikumpulkan menggunakan search engine dan pengambilan data primer ke lapangan. Pada tahapan pengambilan data primer ke lapangan kita mengambil data menggunakan kamera Canon PowerShot SX420 IS dengan lensa kamera 20 Megapixel, ISO600 dan aperture f/5.6. Pengambilan data dilakukan pada kota Cirebon dengan mengambil sampel dari beberapa ahli topeng yang berkediaman disana.

Penelitian ini melakukan dua pendekatan dalam melakukan pengambilan data untuk membuat data lebih berbeda. Hasil yang didapatkan dari tahapan ini adalah terdapat 30 gambar / kelas untuk pendekatan pertama dan 172 gambar / kelas untuk pendekatan kedua.

Tabel 1. Total Dataset dari Pendekatan 1 dan Pendekatan 2

\begin{tabular}{|l|l|}
\hline Pendekatan 1 & 150 \\
\hline Pendekatan 2 & 860 \\
\hline Total & 1010 \\
\hline
\end{tabular}

Tabel 2. Distribusi Dataset

\begin{tabular}{|c|c|c|c|}
\hline & train & test & Total \\
\hline Total & 740 & 270 & 1010 \\
Gambar & & 54 & 202 \\
\hline $\begin{array}{c}\text { Total } \\
\text { Gambar } / \\
\text { kelas }\end{array}$ & 148 & 54 & \\
\hline
\end{tabular}

\section{b. Hasil Eksperimen}

Hasil eksperimen dari penelitian ini dapat dilihat pada Tabel 3. Hasil eksperimen juga dibandingkan dengan hasil menggunakan first order statistical feature [2] dan GLCM [1] yang dilakukan oleh Kurniadi menggunakan SVM dan KNN sebagai classifier dan CNN dengan 
konsep transfer learning pada data yang ada. Pada CNN optimizer yang digunakan adalah adam dengan epoch 100.

Tabel 3. Hasil Eksperimen

\begin{tabular}{|c|c|c|}
\hline Metode & classifier & akurasi \\
\hline $\begin{array}{c}\text { First Order } \\
\text { Feature }\end{array}$ & KNN & $74 \%$ \\
\hline & SVM & $46.67 \%$ \\
\hline GLCM & KNN & $92.98 \%$ \\
\hline & SVM & $57.03 \%$ \\
\hline CNN & softmax & $99.48 \%$ \\
\hline
\end{tabular}

Berdasarkan hasil di atas bahwa metode yang CNN memberikan hasil akurasi terbaik dibandingkan dengan menggunakan metode-metode feature crafted seperti GLCM ataupun First Order Feature. Hal ini memberikan gambaran bahwa proses klasifikasi topeng Cirebon menggunakan metode transfer learning sudah sangat baik dibandingkan dengan metode feature crafted lainnya.

\section{SIMPULAN}

Penelitian pengklasifikasian topeng Cirebon menggunakan metode Convolutional Neural Network. Penelitian ini memberikan pandangan baru mengenai proses metode machine crafted seperti CNN dengan transfer learning memberikan pengenalan yang lebih baik dibandingkan dengan metode human crafted seperti GLCM, ataupun First Order Feature.

\section{UCAPAN TERIMA KASIH}

Penulis ingin mengucapkan terima kasih kepada Fendy Hendriyanto sebagai pengumpul data dan penulis juga berterima kasih kepada Kementerian Riset dan Teknologi Republik Indonesia untuk Hibah Penelitian Dosen Pemula (PDP) dengan SK No: 8/E1/KPT/ 2020 dan Kontrak No: 002/05/Hibah/VIII/2020.

\section{DAFTAR PUSTAKA}

[1] F. I. Kurniadi and V. K. Putri, Gray Level Co-ocurence Matrix Untuk Pengekstrasian Ciri Topeng Cirebon, Ultimatics: Jurnal Teknik Informatika, Vol. 12, No. 1, pp. 20-24.

[2] F. I. Kurniadi and F. Hendriyanto. 2019, Cirebon Mask Classification Using Robust KNearest Neighbour, in 2019 International Conference on Information and Communications Technology (ICOIACT), Yogyakarta, Indonesia, Jul. 2019, pp. 143-146, doi: 10.1109/ICOIACT46704.2019.8938499.

[3] B. P. Ida Bagus Gede and A. Harjoko. 2017, Pengenalan Topeng Bali Menggunakan Algoritma Convolutional Neural Network, Master's Thesis, Universitas Gadjah Mada,.

[4] D. M. S. Arsa and A. A. N. H. Susila. 2019, VGG16 in Batik Classification Based on Random Forest, in 2019 International Conference on Information Management and 
Technology (ICIMTech), Jakarta/Bali, Indonesia, Aug. 2019, pp. 295-299, doi: 10.1109/ICIMTech.2019.8843844.

[5] Lasmiyati, 2011, Sejarah Pertumbuhan dan Pengembangan Tari Topeng Cirebon Abad XV-XX, Patanjala, Vol. 3, No. 3, pp. 472-487, Sep. 2011.

[6] Pusat Studi Sunda. 2008, Kujang, Bedog, dan Topeng dan Kajian Lainnya Mengenai Budaya Sunda, Seri Sunda. Pusat Studi Sunda.

[7] M. Yani, S. Budhi Irawan Si. ,. M. T., and S. T. Casi Setiningsih M. T., 2019, Application of Transfer Learning Using Convolutional Neural Network Method for Early Detection of Terry's Nail, J. Phys.: Conf. Ser., Vol. 1201, p. 012052, May 2019, doi: 10.1088/17426596/1201/1/012052.

[8] J. Yosinski, J. Clune, Y. Bengio, and H. Lipson. 2014, How Transferable are Features in Deep Neural Networks?, in Advances in Neural Information Processing Systems 27, Z. Ghahramani, M. Welling, C. Cortes, N. D. Lawrence, and K. Q. Weinberger, Eds. Curran Associates, Inc., , pp. 3320-3328.

[9] K. Simonyan and A. Zisserman. 2020, Very Deep Convolutional Networks for Large-Scale Image Recognition, arXiv:1409.1556 [cs], Apr. 2015, Accessed: Oct. 14, [Online]. Available: http://arxiv.org/abs/1409.1556.

[10]F. I. Kurniadi and V. K. Putri. 2019, A Comparison of Human Crafted Features and Machine Crafted Features on White Blood Cells Classification, J. Phys.: Conf. Ser., Vol. 1201, p. 012045, May 2019, doi: 10.1088/1742-6596/1201/1/012045. 